\title{
The evolution of COVID-19 pandemic wave and optimal levels of vaccination to reduce negative effects in society
}

Mario Coccia ( $\square$ mario.coccia@cnr.it)

National Research Council of Italy

\section{Research Article}

Keywords: Pandemic diseases, SARS-CoV-2, Coronavirus, Virus transmission, COVID-19 vaccines, Rollout, Vaccination campaigns, Public health, Health planning, Herd immunity, Epidemiology, Crisis management

Posted Date: September 27th, 2021

DOI: https://doi.org/10.21203/rs.3.rs-941879/v1

License: (9) This work is licensed under a Creative Commons Attribution 4.0 International License.

Read Full License 


\title{
THE EVOLUTION OF COVID-19 PANDEMIC WAVE AND OPTIMAL LEVELS OF VACCINATION TO REDUCE NEGATIVE EFFECTS IN SOCIETY
}

\author{
MARIO COCCIA \\ RESEARCH DIRECTOR \\ CNR -- NATIONAL RESEARCH COUNCIL OF ITALY \\ Via Real Collegio, n. 30 \\ (Collegio Carlo Alberto) \\ 10024 - Moncalieri (TO), Italy
}

ContactE-mail: mario.coccia@cnr.it

\begin{abstract}
Coronavirus disease 2019 (COVID-19) continues to be a pandemic threat with new mutations of the viral agent (SARS-CoV 2) that are generating a constant state of attention in manifold countries. Innovative drugs, such as vaccines can sustain, as far as possible, immunity of people and decrease negative effects in society. The study here, using data of vaccines and confirmed cases of COVID-19 between countries from March to May 2021, clarifies different optimal levels of vaccination associated with the growth of pandemic wave for reducing infected individuals in society. Findings reveal that a vaccination campaign in the initial phase of pandemic wave has a lower optimal level of doses administered per 100 inhabitants, but the growth of pandemic wave moves up the optimal level of vaccines from 58.5 in March to more than 86 doses per 100 people in May 2021. This study suggests that the optimal strategy and response to pandemic crisis is a rapid vaccination rollout, before the takeoff of pandemic wave, for an effective response to reduce numbers of COVID-19 related infected individuals and deaths and negative effects of pandemic crisis on environment and socioeconomic systems.
\end{abstract}

Keywords: Pandemic diseases, SARS-CoV-2, Coronavirus, Virus transmission, COVID-19 vaccines, Rollout, Vaccination campaigns, Public health, Health planning, Herd immunity, Epidemiology, Crisis management.

\section{Declaration of competing interest}

The author declares that he is the sole author of this manuscript and he has no known competing financial interests or personal relationships that could have appeared to influence the work reported in this paper.

This study has none funders. 


\section{INTRODUCTION}

Coronavirus disease 2019 (COVID-19) is an infectious illness caused by the novel Severe Acute Respiratory Syndrome Coronavirus 2 (SARS-CoV-2), which appeared in late 2019 (Anand et al., 2021; Bontempi et al., 2020, 2021; Bontempi and Coccia, 2021; Coccia, 2021). COVID-19 is still circulating in 2021 with mutations of the novel coronavirus $^{1}$ that generate continuous COVID-19 infections and deaths in manifold countries (Johns Hopkins Center for System Science and Engineering, 2021; Vicenti et al., 2021). Seligman et al. (2021) show some characteristics of people that are significantly associated with COVID-19 mortality, such as: " mean age 71.6 years, ... disproportionate deaths occurred among individuals with nonwhite race/ethnicity (54.8\% of deaths ...p $<0.001)$, individuals with income below the median $(67.5 \% \ldots \mathrm{p}<0.001)$, individuals with less than a high school level of education $(25.6 \% \ldots \mathrm{p}<0.001)$, and veterans $(19.5 \% \ldots \mathrm{p}<0.001) "$. High numbers of COVID-19 related infected individuals and deaths worldwide have supported the development of innovative products ${ }^{2}$ given by different types of vaccines from 2020 based on viral vector, protein subunit and nucleic acid (RNA). In vector vaccines, genetic material from the COVID-19 virus is placed in a modified version of a different virus (called, viral vector). When the viral vector gets into human cells, it delivers genetic material from the COVID-19 virus directed to instruct the cells to make copies of the S protein (the main protein used as a target in COVID-19 vaccines). After that, human cells display the $\mathrm{S}$ proteins on their surfaces and immune system responds by creating antibodies and defensive white blood cells to fight the novel coronavirus (Janssen/Johnson \& Johnson and University of Oxford/AstraZeneca have generated viral vector vaccines for COVID-19). Protein subunit vaccine includes only the parts of a virus that best stimulate immune system. This type of COVID-19 vaccine has harmless S proteins. The immune system recognizes S proteins and creates antibodies and defensive white blood cells to fight the viral agent (e.g., American biotechnology company Novavax has developed this type of vaccine; cf., GAVI, 2021). Instead, the Messenger RNA (mRNA) vaccines use genetically engineered mRNA to give to cells instructions for how to make the $\mathrm{S}$ protein found on the surface of the COVID-19 virus, creating antibodies to fight the novel coronavirus (Mayo Clinic, 2021). The process

1 WHO considers the following variants of concern: Beta, Gamma and Delta; Variants of interest (Lambda and Mu) and manifold variants under monitoring (ECDC, 2021).

2 About the sources and evolution of innovation cf., Coccia, 2015, 2016, 2016a; 2017a, 2017c, 2017d, 2019a, 2019b, 2020d, 2020e; Coccia and Watts, 2020. 
of development of mRNA vaccines for COVID-19 is much faster than conventional vaccines to be redesigned and mass-produced (Abbasi, 2020; Calabrese et al., 2005; Cylus et al., 2021; Heaton, 2020; Jeyanathan et al., 2020; Komaroff, 2020). The first mRNA COVID-19 vaccines are due to premier biopharmaceutical companies: PfizerBioNTech and the Moderna (cf., Coccia, 2021a). In the presence of COVID-19 pandemic crisis, the investigation of vaccination plans is a crucial aspect to determine how the novel infectious disease can be controlled and/or eradicated in the population (Aldila et al., 2021). Vaccination has the potential effect to reduce the diffusion COVID-19, to relax nonpharmaceutical measures and maintain low basic reproduction number, but an important point to clarify is the optimal strategy of administering the vaccines during the evolution of COVID-19 pandemic wave to reduce negative effects in society (cf., Anser et al., 2020). Akamatsu et al. (2021) argue the vital role of governments is directed to implement an efficient campaign of vaccination to substantially reduce infections and mortality in society and also avoid the collapse of healthcare system. Aldila et al. (2021) maintain that higher levels of vaccination rate can eradicate COVID-19 in population by approaching herd immunity to protect vulnerable individuals (cf., Anderson et al., 2020; de Vlas and Coffeng, 2021; Jones and Helmreich, 2020; Randolph and Barreiro, 2020; Redwan, 2021). Herd immunity indicates that only a share of population needs to be immune and as a consequence no longer susceptible to a viral agent (by overcoming natural infection or through vaccination) for control of large outbreaks (Fontanet and Cauchemez, 2020). Scholars can estimate the proportion of a population that needs to be immune to support herd immunity, ceteris paribus. The threshold level depends on basic reproduction number, $\mathrm{R}_{0}$ — the number of cases, on average, spawned by one infected individual in an otherwise fully susceptible (Coccia, 2020; Kwok et al., 2020). In particular, the formula for calculating the herd-immunity threshold is $1-1 / R_{0}$ and it indicates that the more people who become infected by each individual who has the virus, the higher the proportion of the population that needs to be immune to reach herd immunity. The index $\mathrm{R}_{0}$ assumes that everyone is susceptible to the virus, but the level changes as the epidemic proceeds, since it depends on changes in susceptibility of the population, mitigation policies, circulation of variants, etc. (Aschwanden, 2020, 2021). Kwok et al. (2021) estimated the Rt and threshold level for herd immunity in different country's population. The estimates of effective reproduction number (Rt) range from 1.06 to 6.64 and the minimum proportion (\%) of total population required to recover from COVID-19 to confer immunity (P crit) is 5.66 in Kuwait and 85 in Bahrain. The estimates of Rt also depend on measures of 
mitigation and containment that if they are relaxed can move up herd-immunity threshold (Buss et al., 2021; Dashtbali and Mirzaie, 2021). Rosen et al. (2021) describe socioeconomic and organizational factors associated with the success of vaccination campaign in Israel as well as they show some aspects of misinformation that can reduce the effectiveness of a fruitful vaccination plan over time (cf., Prieto Cruriel, et al. 2021). In this context, a vital problem in current COVID-19 pandemic crisis is the effective level of vaccination that supports a drastic reduction of COVID-19 infected individuals and deaths. The study confronts this problem here by developing a statistical analysis to explain, whenever possible at global level, the different optimal levels of vaccination during the evolution of COVID-19 pandemic wave that trigger a reduction of infected individuals in society. Results can suggest best practices of optimization in the vaccination strategy in order to guide effective and timely policy responses for combatting the novel coronavirus and constraining negative effects of COVID-19 pandemic crisis and future epidemics of similar infectious diseases in society. Findings of this study could be also of benefit to countries as they grapple to plan their vaccine programmes for COVID-19 pandemic crisis to minimize negative effects of pandemic crisis on environment and socioeconomic systems. This study is part of a large body of research project directed to explain drivers of transmission dynamics of COVID-19 and design effective policy responses to cope with and/or to prevent pandemic threats (Coccia, 2020, 2020a, 2020b, 2020c, 2021, 2021c, 2021d, 2021e, 2021i, 2022).

\section{DATA AND STUDY DESIGN}

\subsection{Sample and period}

The sample of this study is based on $N=192$ countries worldwide. Period under study is from March to May 2021, using data of vaccines, confirmed cases and fatality rate of COVID-19.

- Measures of variables

- $\quad$ Doses of vaccines administered $\times 100$ inhabitants on 15 March 2021 with $N=114$ countries; on 14 April 2021 with $N=154$ countries and on 26 April 2021 with $N=190$ countries. The number of sample tends to increase over time with the diffusion of vaccines across countries worldwide. Doses of vaccines refer to the total number of vaccine doses, considering that an additional dose may be obtained from each vial (e.g., six doses for Pfizer BioNTech ${ }^{\circledR}$ Comirnaty), whereas number of doses administered refers to any individual receiving any dose of the vaccine (cf., Freed et al., 2021; Oliver et al., 2020). The data here considers all types of COVID- 
19 vaccines used in different countries, i.e., vaccines by Johnson \& Johnson, Oxford/AstraZeneca, Pfizer/BioNTech, Sinopharm/Beijing, Sinovac, Sputnik V and Moderna (Ritchie et al., 2020). Of course every country has been using a different combination of these COVID-19 vaccines to protect the population (CBC, 2021; CDC, 2021; Rossman et al., 2021). Source: Our World in Data (2021).

- $\quad$ Number of COVID-19 infected individuals (\%) is measured with confirmed cases of COVID-19 divided by population of countries under study on 20 March 2021 ( $N=192$ countries), 25 April 2021 ( $N=192)$ and 19 May 2021 ( N=216 countries). Source of data: Johns Hopkins Center for System Science and Engineering (2021).

- $\quad$ Number of COVID-19 deaths is measured with fatality rate (\%)given by deaths on 25 April 2021 divided by total infected individuals in each countries. Source of data: Johns Hopkins Center for System Science and Engineering (2021).

\subsection{Data analysis procedure and scenarios}

Firstly, data are analyzed with descriptive statistics of variables given by arithmetic mean (M) and standard error of the mean (SEM). Data concerning doses of COVID-19 vaccines and confirmed cases of a specific day in the dataset can refer to different days because of the difficulty in countries associated with gather or transmission of information. Moreover, database here includes different COVID-19 vaccines having a different period of administration between the first and second dose to provide a certain level of protection that begins after a variable number of days (approximately after 12 - 14 days the first dose) and remains for some months (about six months). The intrinsic problems of the database, just mentioned, based on data of different countries lead to not consider in the statistical analyses here a specific interval between the date of vaccination of people and date of confirmed cases to detect the optimal levels of vaccination, because we consider the sample of countries as a whole having a normal distribution that mitigates discrepancies among countries (cf., Coccia, 2018).

We assume different scenarios considering the evolution of COVID-19 pandemic wave and vaccination over time:

- Scenario I. Initial phase of COVID-19 pandemic wave in March 2021. If countries of the sample had the level of vaccination at the time $t$ (March) and pandemic wave had the confirmed cases $t$ ' of the same month (March), how would be the optimal level of vaccination

- Scenario II. Growth phase of COVID-19 pandemic wave in April 2021, whereas level of vaccination is of March 
2021. If countries of the sample had the level of vaccination at the time $t$ (March) and confirmed cases of the following month $t+1$ (April), how would be the optimal level of vaccination

- Scenario III. Maturity phase of COVID-19 pandemic wave in May 2021, whereas the level of vaccination refers to April 2021. If countries of the sample had the level of vaccination at the time $t$ (April 2021) and confirmed cases of the following month $t+1$ (May 2021), how would be the optimal level of vaccination.

Secondly, the analysis of simple regression applies quadratic models because they fit the scatter of data to detect nonlinear effects of relations understudy.

The specification of model is given by:

$y_{i, t}=\alpha_{0}+\beta_{1} \mathrm{x}_{\mathrm{i}, \mathrm{t}-1}+\beta_{2} \mathrm{x}_{\mathrm{i}, \mathrm{t}-1}^{2}+u_{i, t}$

where:

○ $y_{i, t}=$ Response variable is the number of COVID-19 infected individuals/population

○ $x_{i, t-1}=$ Doses of vaccines administered $\times 100$ inhabitants, explanatory variable

$\bigcirc \quad u_{i, t}=$ Error term

○ country $i=1, \ldots, n ; \quad t=$ time

Remark: Model [1] has a time lag effect between explanatory ( $t-1)$ and dependent variables ( $t$ ) to reduce the endogeneity and provide reliable (estimated) parameters.

Remark: The square of the doses of vaccines administered $\times 100$ inhabitants in model [1] is introduced to consider the possibility of non-linear effects in the relation under study.

Thirdly, the optimization of the estimated relationship [1] is performed with the following perspective: the maximization of the equation [1] to find the optimal levels of doses of vaccines administered $\times 100$ inhabitants (during the annual cycle of evolution of the COVID-19 pandemic) that support a consequential drastic reduction of confirmed cases of COVID-19 and negative effects in society. In particular, the estimated relationships [1] are objective functions of one (real) variable represented by polynomial functions of an order higher than first order (i.e., second order). These estimated relations [1] are continuous and infinitely differentiable functions. The calculus applied on functional 
relation [1] provides the optimal levels of doses of vaccines administered $\times 100$ inhabitants at the time $t$ (in a specific stage of COVID-19 pandemic wave as indicated in scenarios A, B and C) that reduces the spread of confirmed cases in society.

Finally, the effects of vaccines on fatality rate are analyzed with a bivariate correlation (1-talied) and a simple regression analysis given by following $\log$ - $\log$ model:

$f_{i, t}=\delta_{0}+\delta_{1} \mathrm{v}_{\mathrm{i}, \mathrm{t}-1}+\varepsilon_{i, t}$

where:

$\circ f_{i, t}=$ Fatality rate, dependent variable

$\circ v_{i, t-1}=$ Doses of vaccines administered $\times 100$ inhabitants, explanatory variable

$\bigcirc \quad \varepsilon_{i, t}=$ Error term

○ country $i=1, \ldots, n ; \quad t=$ time

In addition, the quartiles of distribution of doses of vaccines administered between countries in April 2021 are used to analyze the average fatality rate $(\%)$ from the first quartile (25th percentile) that includes countries having a lower number of doses of vaccine per 100 inhabitants to the fourth quartile including countries with the highest number of doses of vaccine per 100 inhabitants. Statistical analyses are performed with the Statistics Software SPSS $®$ version 26.

\section{RESULTS}

Table 1 shows that number of countries having doses vaccines per 100 inhabitants grows from March to April 2021 because new nations start vaccination campaigns and more data are gathered and transmitted in the progress of vaccination across countries worldwide. The number of countries with confirmed cases of COVID-19 cases also grows over time because other countries gather and transmit new data.

Table 1. Descriptive statistics

\begin{tabular}{llcccc}
\hline Variables & & $\mathrm{N}$ & Mean & Std. Error \\
\hline Doses vaccines per 100 inhabitants & 15 March 2021 & 114 & 8.85 & 1.46 \\
Doses vaccines per 100 inhabitants & 26 April 2021 & 192 & 22.13 & 2.17 \\
Confirmed Cases /population \% & 20 March 2021 & 192 & 2.57 & 0.23 \\
Confirmed Cases /population \% & 25 April 2021 & 192 & 3.04 & 0.26 \\
Confirmed Cases /population \% & 19 May 2021 & 216 & 2.95 & 0.003
\end{tabular}

$N=$ number of cases (countries) 
Phase I (initial) of COVID-19 pandemic wave in March 2021.

Table 2. Regression analyses of confirmed cases/population of 20 March on doses of vaccines on 15 March 2021 based on quadratic model [1]

$\begin{array}{rl}\text { Constant } \alpha & 2.09 \text { *** } \\ (\text { St. Err }) & (.38) \\ \text { Coefficient } \beta_{1} & .234^{* * *} \\ \text { (St. Err.) } & (.05) \\ \text { Coefficient } \beta_{2} & -.002^{* * *} \\ \text { (St. Err.) } & (.001) \\ \mathrm{R}^{2} & .22 \\ \text { (St. Err. of Estimate) } & (2.95) \\ F & 16.43^{* * *} \\ N & 113\end{array}$

Note: Dependent variable is Confirmed cases/population (\%) of 20 March 2021. Explanatory variable is doses of vaccines on 15 March 2021 per 100 inhabitants.

Significance: ${ }^{* * *} p$-value $<0.001$

The estimated relationship, based on results of table 2 , is:

$$
z_{i, t}=2.09+0.234 h_{\mathrm{i}, \mathrm{t}-1}-0.002 h_{\mathrm{i}, \mathrm{t}-1}^{2}
$$

The polynomial function is given by

$$
z=2.09+0.234 h-0.002 h^{2}
$$

the necessary condition to maximize is:

$\frac{d z}{d h}=z^{\prime}(b)=0.234-0.004 h=0$

The first derivative equal to 0 is:

$$
z^{\prime}(b)=0 \quad \Rightarrow b^{*}=\frac{0.234}{0.004}=58.5 \text { per } 100 \text { inhabitants }
$$

$b^{*}=58.5$ per 100 people indicates the optimal level of doses of vaccines in the initial phase of pandemic wave, after that the function of confirmed cases has a sharply decrease that reduces the negative impact and diffusion of COVID19 leading, whenever possible, to constraint the pandemic crisis in society. 


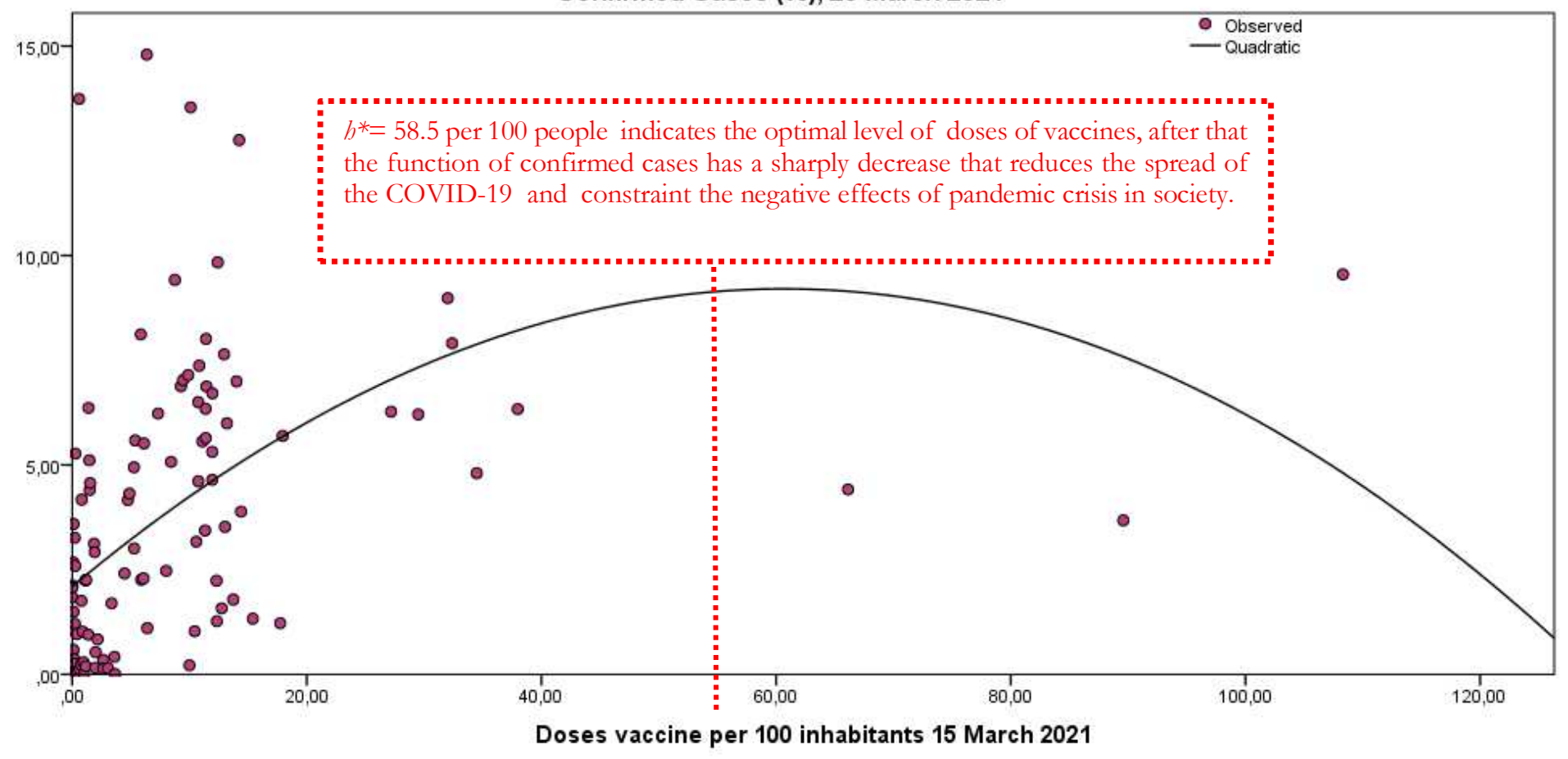

Figure 1. Relation of confirmed cases/population (\%) of 20 March 2021 on doses of vaccines on 15 March 2021 based on quadratic model [1]

Phase II, the growth of COVID-19 pandemic wave in April 2021 and level of vaccination in March.

Table 3. Regression analyses of confirmed cases/population (\%) of 25 April on doses of vaccines on 15 March 2021 based on quadratic model [1]

\begin{tabular}{rr} 
Constant $\alpha$ & $2.47 * * *$ \\
(St. Err) & $(.43)$ \\
Coefficient $\beta_{1}$ & $.281 * * *$ \\
(St. Err.) & $(.05)$ \\
Coefficient $\beta_{2}$ & $-.002^{* * *}$ \\
(St. Err.) & $(.001)$ \\
$\mathrm{R}^{2}$ & .23 \\
rr. of Estimate) & $(3.35)$ \\
$F$ & $17.58^{* * *}$ \\
$N$ & 113 \\
\hline
\end{tabular}

Note: Dependent variable is Confirmed cases/population (\%) of 25 April 2021. Explanatory variable is doses of vaccines on 15 March 2021 per 100 inhabitants.

Significance: $* * * p$-value $<0.001$ 
The estimated relationship, based on results of table 3, is:

$$
y_{i, t}=2.47+0.281 x_{\mathrm{i}, \mathrm{t}-1}-0.002 \mathrm{x}_{\mathrm{i}, \mathrm{t}-1}^{2}
$$

The function to optimize is given by

$$
f=2.47+0.281 x-0.002 \mathrm{x}^{2}
$$

the necessary condition to maximize is:

$\frac{d f}{d x}=f^{\prime}(x)=0.281-0.004 x=0$

The first derivative equal to 0 is:

$$
f^{\prime}(x)=0 \Rightarrow \quad x^{*}=\frac{0.281}{0.004}=70.25 \text { per } 100 \text { inhabitants }
$$

$x^{*}=70.25$ per 100 people indicates the optimal level of doses of vaccines during the phase of growth (April) of pandemic wave, after that the function of confirmed cases has a sharply decrease that reduces the negative impact and diffusion of COVID-19 leading, whenever possible, to constraint the pandemic crisis in society.

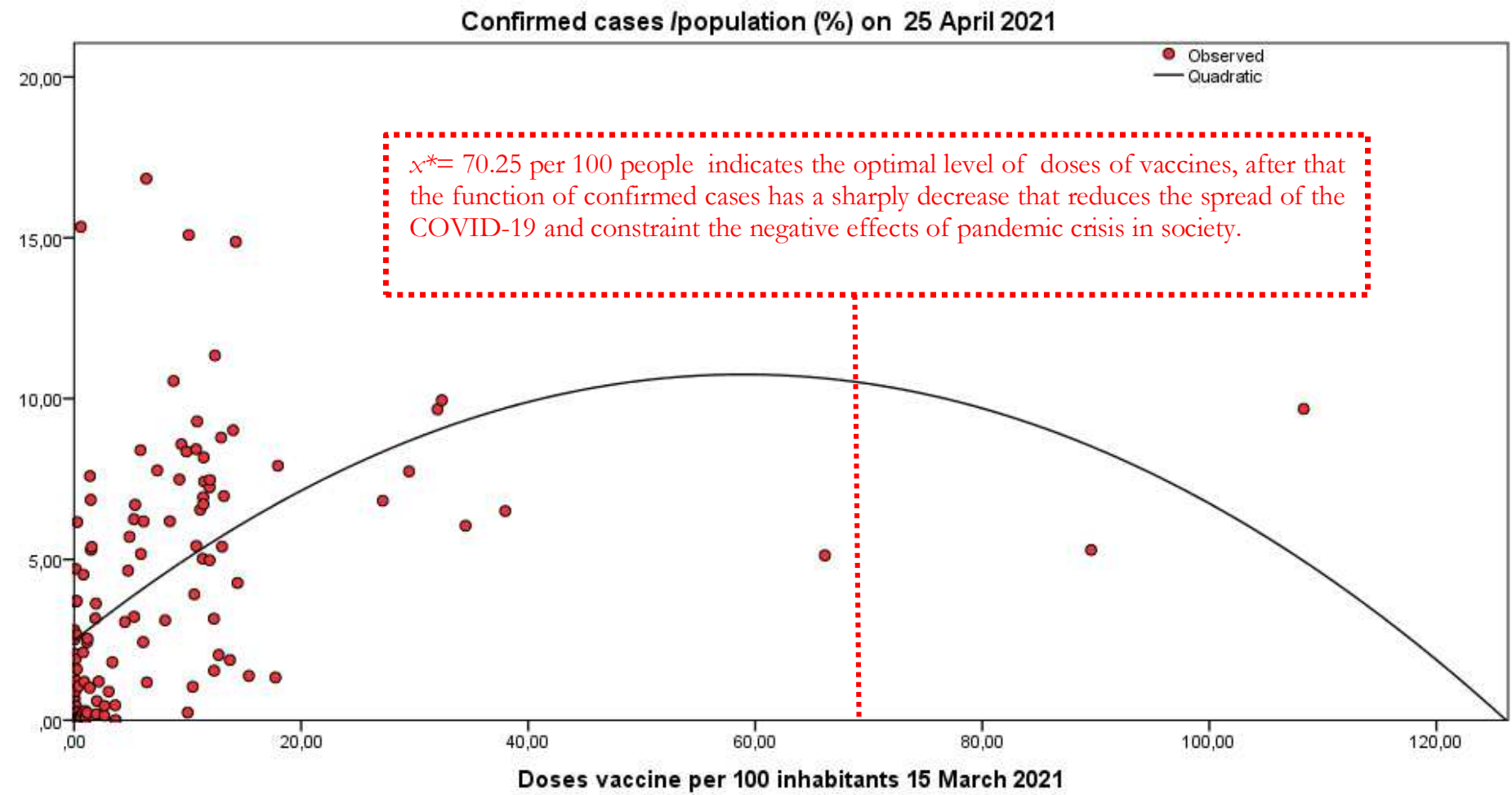

Figure 2. Relation of confirmed cases/population (\%) of 25 April on doses of vaccines 15 March 2021 based on quadratic model [1] 
Phase III, maturity of COVID-19 pandemic wave in May 2021 and level of vaccination in April 2021.

Table 4. Regression analyses of confirmed cases/population of 19 May 2021 on doses of vaccines on 26 April 2021 based on quadratic model [1]

\begin{tabular}{rr}
\hline Constant $\alpha$ & $.020 * * *$ \\
$($ St. Err $)$ & $(.004)$ \\
Coefficient $\beta_{1}$ & $001 * * *$ \\
(St. Err.) & $(.000)$ \\
Coefficient $\beta_{2}$ & $-.000005789 * * *$ \\
$($ St. Err.) & $(.000)$ \\
$\mathrm{R}^{2}$ & .11 \\
(St. Err. of Estimate) & $(.037)$ \\
$F$ & $12.16^{* * *}$ \\
$N$ & 191 \\
\hline
\end{tabular}

Note: Dependent variable is Confirmed cases/population of 19 May 2021. Explanatory variable is Doses of vaccines on 26 April 2021 per 100 inhabitants.

Significance: ${ }^{* * *} p$-value $<0.001$

The estimated relationship, based on results of table 4, is:

$$
j_{i, t}=0.02+0.001 w_{\mathrm{i}, \mathrm{t}-1}-0.000005789 \mathrm{w}_{\mathrm{i}, \mathrm{t}-1}^{2}
$$

The function to optimize is given by

$$
j=0.02+0.001 w-0.000005789 \mathrm{w}^{2}
$$

the necessary condition to maximize is:

$\frac{d j}{d w}=j^{\prime}(w)=0.001-0.000011578 w=0$

The first derivative equal to 0 is:

$$
j^{\prime}(w)=0 \Rightarrow \quad w^{*}=\frac{0.001}{0.000011578}=86.37 \text { per } 100 \text { inhabitants }
$$

$w^{*}=86.37$ per 100 people indicates the optimal level of doses of vaccines in the phase of maturity of pandemic wave (May 2021), after that the function of confirmed cases has a sharply decrease that reduces the negative impact and 
diffusion of COVID-19 leading, whenever possible, to constraint the negative societal effects of pandemic crisis in countries.

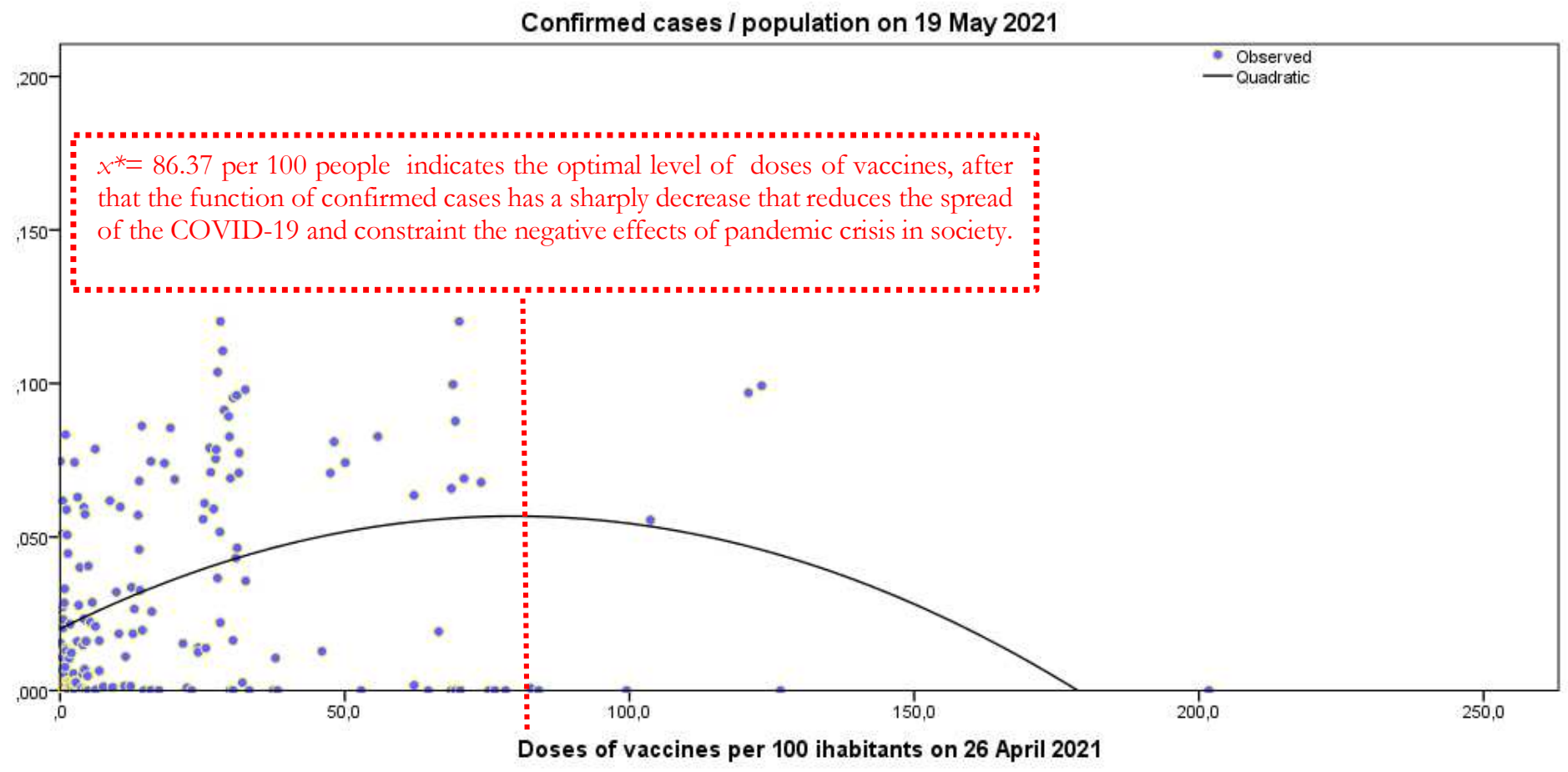

Figure 3. Relation of confirmed cases/population (\%) of 19 May 2021 on doses of vaccines 26 April 2021 based on quadratic model [1]

\section{Effects of vaccination on fatality rate of COVID-19}

Table 5. Correlation

$\begin{array}{cc}\text { Log Doses vaccines } & \text { Log Doses vaccines } \\ \text { per100 inhabitant } & \text { per100 inhabitant } \quad \text { Log Fatality Rate }\end{array}$

15 March 2021 14April 21 25 April 21

Log Doses vaccines per100 inhabitant 15 March 2021

1

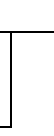

$932 * *$

0.001

0.026

Log Doses vaccines per100

inhabitant 14 April 2021

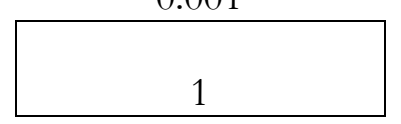

$-.236^{* *}$

0.002

Log Fatality Rate

25 April 2021

1

** Correlation is significant at the 0.01 level (1-tailed).

* Correlation is significant at the 0.05 level (1-tailed).

Table 5 shows bivariate correlation of variables under study: fatality rates have a moderate negative association with doses vaccines per100 inhabitant on 15 March $2021(r=-.19, p$-value $<.05)$ and doses vaccines per100 inhabitant on 14 April $2021(r=-.24$, $p$-value $<.01)$. 
Table 6. Regression analyses of log fatality rate of the 25 April 2021 on log doses of vaccines per 100 inhabitants of the 14 April 2021 based on liner model [2]

\begin{tabular}{rr} 
Constant $\alpha$ & $.54 * * *$ \\
(St. Err) & $(.078)$ \\
Coefficient $\beta_{1}$ & $-.09 * *$ \\
(St. Err.) & $(.032)$ \\
$\mathrm{R}^{2}$ & .06 \\
(St. Err. of Estimate) & $(.75)$ \\
$\mathrm{F}$ & $8.54 * *$ \\
Significance: ${ }^{* * *} p$-value $<0.001{ }^{* *} p$-value $<0.01$ & 191 \\
\hline
\end{tabular}

Table 6 shows the coefficient of regression that indicates how an increase of $1 \%$ of doses of vaccines, it reduces the expected fatality rate by approximately $0.09 \%(p$-value $=.01)$. However, the coefficient $\mathrm{R}^{2}$ is rather low.

Figure 4. Average fatality rate at 25 April 2021 in different quartiles of the distribution of doses of vaccines per 100 inhabitants on 14 April 2021

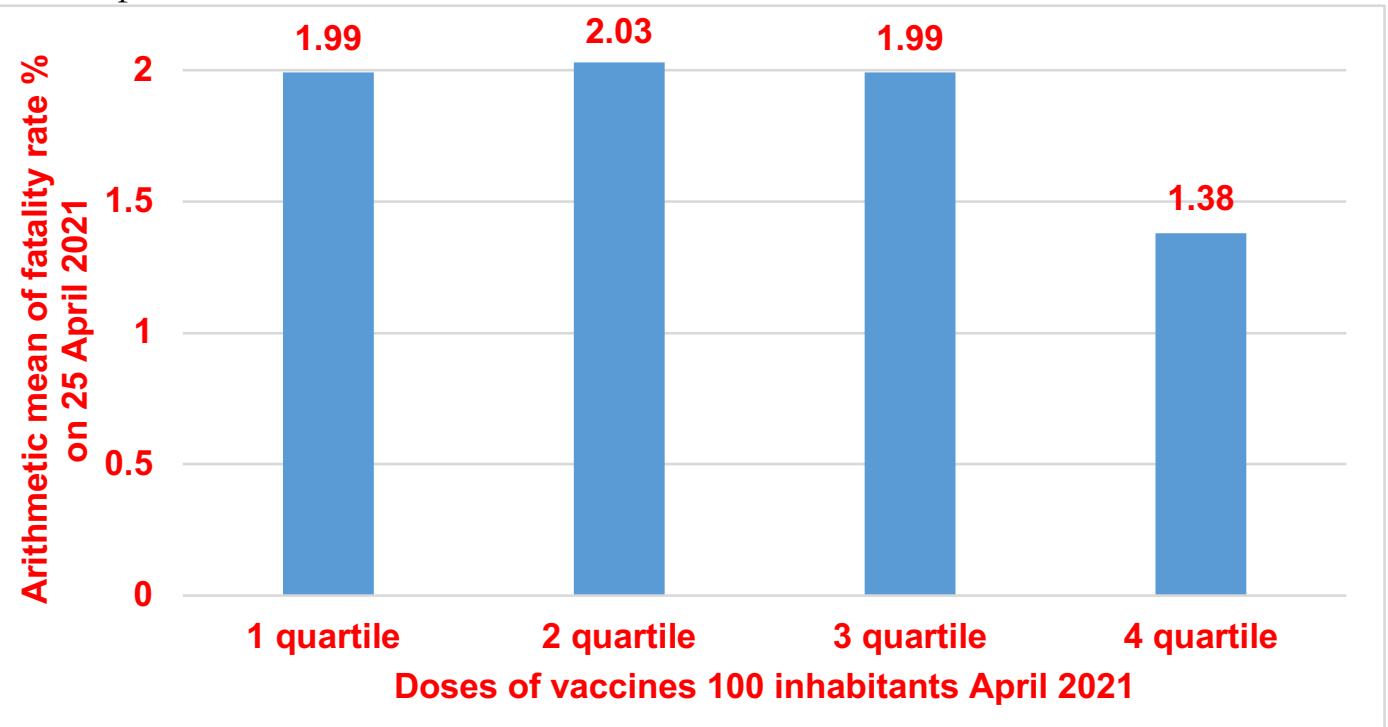

Note: the $1^{\text {st }}$ quartile (25th percentile) includes countries having a lower number of doses of vaccines per 100 inhabitants $(\leq .83), 2^{\text {nd }}$ quartile $(.83-5.79), 3^{\text {rd }}$ quartile $(\leq 5.79-22.43)$, $4^{\text {th }}$ quartile has countries with the highest number of doses of vaccines per 100 inhabitants $>22.43)$.

In general, these results suggest that the higher levels of vaccination generates a moderate reduction of fatality rate of COVID-19 in society, also considering that COVID-19 pandemic is going towards summer season characterized by a natural reduction of infected people (Figure 4). 


\section{DISCUSSION}

The main findings of the study here can be summarized in table 7 . In particular, results reveal that optimal level of vaccination is associated with the evolution of COVID-19 pandemic wave: a vaccination in the initial phase of pandemic wave has a lower optimal level of doses administered per 100 inhabitants to reduce infected individuals, but the growth of pandemic wave moves up the optimal level of vaccines from 58.5 (March 2021) to more than 86 doses per 100 people (May 2021) with consequential effects on socioeconomic systems. This study suggests that the optimal strategy and response to pandemic crisis is a rapid vaccination rollout, before the takeoff of pandemic wave, for an effective response to reduce numbers of infected individuals and deaths.

Table 7. Optimal levels of vaccination based on relation between confirmed cases and doses of vaccines in different phases of pandemic wave to constrain the diffusion of COVID-19 in society

\begin{tabular}{lc}
\hline $\begin{array}{l}\text { Scenarios based on different phases of } \\
\text { COVID-19 pandemic wave in 2021 }\end{array}$ & $\begin{array}{c}\text { Optimal level } \\
\text { of doses per 100 inhabitants that triggers } \\
\text { the sharply decline of infected individuals }\end{array}$ \\
\hline I (initial stage, March) & 58.50 \\
II (growth stage, April) & 70.25 \\
III (maturity stage, May) & 86.37 \\
\hline
\end{tabular}

These results may be interpreted through the lens of different studies that focus on a large number of factors contributing to the success of implementing the vaccination plan as suggested in the scenario A, having a lower level of doses of vaccines per 100 people for reducing confirmed cases and negative social impact. Sim et al. (2021) compare the coronavirus pandemic in Israel and the UK, showing the importance of factors influencing the early days of the rollout of vaccination and learning processes that can provide main lessons for other countries to plan COVID-19 vaccine programmes. Rosen et al. (2021) indicate three groups of facilitating factors for vaccination plan in Israel:

- extrinsic factors to health care (small size in terms of both area and population), a relatively young population, warm weather in December 2020, a centralized national system of government, and well-developed infrastructure for implementing prompt responses to large-scale national emergencies

- health-system specific factors, such as the organizational, IT and logistical capacities of community-based health care providers, the availability of well-trained cadre, a tradition of effective cooperation between government, 
health plans, hospitals, and emergency care providers - particularly during national emergencies; and support tools and decision-making frameworks to support vaccination campaigns

- finally, specific factors to the COVID-19 vaccination effort: the mobilization of special government funding for vaccine purchase and distribution, timely contracting for a large amount of vaccines relative to population, the use of simple, clear and easily implementable criteria for determining who had priority for receiving vaccines in the early phases of the distribution process, technical response that addressed the demanding cold storage requirements of the Pfizer-BioNTech COVID-19 vaccine, and outreach efforts to encourage people to sign up for vaccinations and then show up to get vaccinated (cf., McKee and Rajan, 2021).

The most important policy implications of findings here are that, though high vaccination efforts of most advanced countries worldwide, the theoretical threshold for vanquishing COVID-19 seems to be out of reach at national and global level because of the accelerated diffusion of COVID-19 pandemic that changes the optimal level every month, the inequality of speed and distribution of vaccines, the ambiguities if and how vaccines prevent or not the transmission, the duration of immunity of vaccinated people and new variants that modify the herd-immunity equation (cf., Aschwanden, 2020, 2021). This study also reveals that high levels of vaccination can reduce slightly fatality rates of COVID-19 but optimal strategies to pandemic shocks should be based on strong governance structures driven by adequate and effective leadership that engages with the communities and adjusts to population needs (Williams et al., 2020). In fact, an organized public governance can support preparedness of nations for performing efficient campaigns of vaccination to reduce infections, mortality, morbidity, stress among the population and support economic recovery (Ardito et al., 2021; Coccia, 2005; Coccia, 2017, 2019, 2021e, 2021f, 2022; Kluge et al., 2020). The public governance supporting efficient vaccination plans is not limited to health system but it involves other functions of nation and its government to work properly for strengthening health, economic and social systems (Sagan et al., 2020). In general, effective crisis management of COVID-19 pandemic should implement timely vaccine programmes (as indicated in scenario A described before) supported by effective multi-level governance to improve health and social safety (Abuza, 2020; Anttiroiko, 2021; DeRoo et al., 2020; Frederiksen et al., 2020; Harrison and Wu, 2020; Ritchie et al., 2020). In addition, plans to achieve optimal levels of vaccination in the initial stage of pandemic have to face distribution and allocation hurdles, and in the presence of delays, they have to cope with 
changes into the equation of herd-immunity with a strategy of vaccination directed to increase the thresholds of immunization of population to reduce, whenever possible, infected individuals in society (Callaway, 2021; Vignesh et al., 2020). In fact, the study here clearly shows that a delay of vaccinations from March to April 2021, in the presence of an evolutionary growth of pandemic wave, it moves forward the optimal threshold between countries from about 59 to 86 doses of vaccines per 100 people to trigger the reduction of the transmission dynamics of COVID-19 (Buss et al., 2021; ECDC, 2021; Mallapaty, 2021; Whittaker et al., 2021). In short, the timely achievement of the optimal threshold of doses administered is a basic aspect of crisis management, because a quickly and thoroughly vaccination plan can reduce mutations of the novel coronavirus, constrain transmission dynamics and consequential socioeconomic issues (Akamatsu, 2021; Byun et al., 2021; Liu et al., 2021). Engelbrecht and Scholes (2021) argue that if effective strategies of vaccination and/or vaccination plans have delayed, the progress of pandemic wave may generate additional health and socioeconomic issues. Overall, then, the implementation of optimal level of vaccination as suggested in scenario A is a significant challenge for all countries globally because it is associated with manifold socio-cultural and political-administrative factors, and enormous public investment in health system and research labs (Ethgen et al., 2019; Coccia, 2008, 2018b; 2019, 2021g, 2022; Coccia and Cadario, 2014). Hence, countries can adequately prepare for, prevent, detect, and respond to both epidemics and inevitable pandemics, over the next ten years, with a better governance, innovative partnerships, financial investments, and efficient utilization of economic resources in health and other sectors (Coccia, 2017b; 2018a; 2019c; Coccia and Bellitto, 2018; U.S. Department of Health \& Human Services, 2021).

\section{CONCLUDING REMARKS AND RECOMMENDATIONS}

COVID-19 and future epidemics of novel influenza viruses pose, more and more, a serious threat to security and public health of nations. An influenza pandemic can occur at any time with little warning; any delay in detecting a novel influenza strain; sharing of influenza virus samples; and in developing, producing, distributing, or administering a therapeutic or vaccine could result in significant additional morbidity and mortality, and deterioration of socioeconomic systems (Coccia, 2021, 2021e). The global response to COVID-19 pandemic has pushed the research for detecting factors and aspects associated with a rapid pandemic response in several areas, including vaccine development, distribution, allocation, and administration. This study suggests that efficient strategies of vaccination 
have to be rapid and responsive in the initial phase of COVID-19 pandemic wave for reducing the impact of novel viral agent in society, though this novel infectious disease might not disappear in the short term because of new variants. These results here can help policymakers to design satisfying goals to cope with current infectious diseases with effective vaccination strategies to prevent future outbreaks of the COVID-19 and similar viral agents.

Although this study has provided some interesting results, that are of course tentative, it has several limitations. First, a limitation of the study is the lack of data about doses administered and total vaccinations in manifold countries, mainly in the spring season of the year 2021, also for the difficulty of production and distribution of COVID-19 vaccines worldwide. Second, not all the possible confounding factors that affect the efficacy of vaccination are taken into consideration (such as, length of lockdown, facemask wearing, etc.) and in future they deserve to be controlled for supporting results here. Third, the lack of integration of data with age of vaccinated people (the priority given in many countries to elderly subjects, with a more compromised immune system) may have influenced the results of infected individuals and deaths across countries. Fourth, country-specific health norms may affect the gather and transmission of data, such that unreported confirmed cases and doses of vaccines in manifold countries may be present in database under study here. Antony et al. (2020) argue that the similarity in presentation between COVID19 and influenza can have generated underreported data across countries. Finally, the estimated relationships in this study focus on variables in specific months (based on recent data available) but an extension of period is needed in future development of the research here. Thus, generalizing the results of this research should be done with caution. Future research should consider new data, when available, and when possible also to examine time series of variables within countries to explain more dynamic relations of the phenomena and relationships under study over time and space. Despite these limitations, the results presented here clearly illustrate the critical aspect of the relationship between phases of the evolution of pandemic wave and timing of the vaccination rollout to better support the goal of reducing negative effects of pandemic crisis in society. However, to conclude, there is need for much more detailed research in these topics and this study encourages further investigations for supporting optimal strategies of vaccination plans, using lessons learned of COVID-19, also considering the interaction between the evolution of pandemics and vaccination, and different factors between countries that are not only parameters related to medicine 
but also to other sciences to improve preparedness of countries to face pandemic crisis and/or to control negative

impact on public health, economy and society.

\section{REFERENCES}

Abbasi J. 2020. COVID-19 and mRNA Vaccines-First Large Test for a New Approach. JAMA, 324(12), 11251127. https://doi.org/10.1001/jama.2020.16866

Abuza Z. 2020. Explaining Successful (and Unsuccessful) COVID-19 Responses in Southeast Asia. The Diplomat. Retrieved July 7, 2020, from https://thediplomat.com/2020/04/explaining-successful-andunsuccessfulcovid-19-responses-in-southeast-asia/

Akamatsu, T., Nagae, T., Osawa, M., Satsukawa, K., Sakai, T., Mizutani, D. 2021. Model-based analysis on social acceptability and feasibility of a focused protection strategy against the COVID-19 pandemic. Scientific reports, 11(1), 2003. https://doi.org/10.1038/s41598-021-81630-9

Aldila, D., Samiadji, B.M., Simorangkir, G.M., Khosnaw, S.H.A., Shahzad, M.2021. Impact of early detection and vaccination strategy in COVID-19 eradication program in Jakarta, Indonesia, BMC Research Notes, $14(1), 132$

Anand, U., Cabreros, C., Mal, J., Ballesteros, F., Jr, Sillanpää, M., Tripathi, V., \& Bontempi, E. 2021). Novel coronavirus disease 2019 (COVID-19) pandemic: From transmission to control with an interdisciplinary vision. Environmental research, 197, 111126. https://doi.org/10.1016/j.envres.2021.111126

Anderson, R. M., Vegvari, C., Truscott, J., Collyer, B. S. 2020. Challenges in creating herd immunity to SARSCoV-2 infection by mass vaccination. Lancet (London, England), 396(10263), $1614-1616$. https://doi.org/10.1016/S0140-6736(20)32318-7

Anser M. K., Yousaf Z., Khan M. A., Voo X. H., Nassani A. A., Alotaibi S. M., Abro M., Zaman K. 2020. The impacts of COVID-19 measures on global environment and fertility rate: double coincidence. Air quality, atmosphere, \& health, 1-10. Advance online publication. https://doi.org/10.1007/s11869-020-00865-z

Antony, S. J., Almaghlouth, N. K., Heydemann, E. L. 2020. Are coinfections with COVID-19 and influenza low or underreported? An observational study examining current published literature including three new unpublished cases. Journal of medical virology, 92(11), 2489-2497. https://doi.org/10.1002/jmv.26167

Anttiroiko Ari-Veikko, 2021. Successful Government Responses to the Pandemic: Contextualizing National and Urban Responses to the COVID-19 Outbreak in East and West. International Journal of E-Planning Research (IJEPR), IGI Global, vol. 10(2), pages 1-17, April.

Ardito L., Coccia M., Messeni Petruzzelli A. 2021. Technological exaptation and crisis management: Evidence from COVID-19 outbreaks. R\&D Management, vol. 51, n. 4, pp. 381-392. Special Issue: Providing solutions in emergencies: R\&D and innovation management during Covid-19 Part-2, September 2021, https://doi.org/10.1111/radm.12455

Aschwanden C. 2020. The false promise of herd immunity for COVID-19. Nature. Nov;587(7832):26-28. doi: 10.1038/d41586-020-02948-4. PMID: 33087872.

Aschwanden C. 2021. Five reasons why COVID herd immunity is probably impossible. Nature, 591(7851), 520522. https://doi.org/10.1038/d41586-021-00728-2

Bontempi E., Coccia M., 2021. International trade as critical parameter of COVID-19 spread that outclasses demographic, economic, environmental, and pollution factors, Environmental Research, vol. 201, Article number 111514, PII S0013-9351(21)00808-2, https://doi.org/10.1016/j.envres.2021.111514, ISSN 0013-9351.

Bontempi E., Coccia M., Vergalli S., Zanoletti A. 2021. Can commercial trade represent the main indicator of the COVID-19 diffusion due to human-to-human interactions? A comparative analysis between Italy, France, 
and Spain, Environmental Research, vol. 201, Article number 111529, PII S0013-9351(21)00823-9, https://doi.org/10.1016/j.envres.2021.111529, ISSN 0013-9351

Bontempi E., Vergalli S., Squazzoni F. 2020. Understanding COVID-19 diffusion requires an interdisciplinary, multi-dimensional approach Environ. Res., 188 (2020), p. 109814, DOI: 10.1016/j.envres.2020.109814

Buss L. F., Prete C. A. Jr, Abrahim C., Mendrone A. Jr, Salomon T., de Almeida-Neto C., França R., Belotti M. C., Carvalho M., Costa A. G., Crispim M., Ferreira S. C., Fraiji,N. A., Gurzenda S., Whittaker C., Kamaura L. T., Takecian P. L., da Silva Peixoto P., Oikawa M. K., Nishiya A. S., ... Sabino E. C. 2021. Three-quarters attack rate of SARS-CoV-2 in the Brazilian Amazon during a largely unmitigated epidemic. Science (New York, N.Y.), 371(6526), 288-292. https://doi.org/10.1126/science.abe9728

Byun WS, Heo SW, Jo G, Kim JW, Kim S, Lee S, Park HE, Baek JH. 2021. Is coronavirus disease (COVID-19) seasonal? A critical analysis of empirical and epidemiological studies at global and local scales. Environ Res. 2021 May;196:110972. doi: 10.1016/j.envres.2021.110972..

Calabrese G., Coccia M., Rolfo S. 2005. Strategy and market management of new product development: evidence from Italian SMEs. International Journal of Product Development, vol. 2, n. 1-2, pp. 170-189. https://doi.org/10.1504/IJPD.2005.006675

Callaway E. 2021. Fast-spreading COVID variant can elude immune responses. Nature, 589(7843), 500-501. https://doi.org/10.1038/d41586-021-00121-z

CBC 2021. Politics, Stretch interval between COVID-19 vaccine doses up to 4 months, national advisory committee recommends. https:/www.cbc.ca/news/politics/naci-interval-advice-change-four-months1.5934563\#: :text=2048-

,Canada's\%20National\%20Advisory\%20Committee\%20on\%20Immunization\%20(NACI)\%20now\%20says\%2 0the,number\%20of\%20Canadians\%20being\%20vaccinated. (Accessed May, 2021)

CDC 2021. Centers for disease control and prevention, Interim Clinical Considerations for Use of COVID-19 Vaccines Currently Authorized in the United States. https:/www.cdc.gov/vaccines/covid-19/info-byproduct/clinical-considerations.html (Accessed May 2021).

Coccia M. 2005. Countrymetrics: valutazione della performance economica e tecnologica dei paesi e posizionamento dell'Italia, Rivista Internazionale di Scienze Sociali, vol. CXIII, n. 3, pp. 377-412. Stable URL: http://www.jstor.org/stable/41624216.

Coccia M. 2008. Measuring scientific performance of public research units for strategic change. Journal of Informetrics, vol. 2, n. 3, pp. 183-194. https://doi.org/10.1016/j.joi.2008.04.001

Coccia M. 2015. Spatial relation between geo-climate zones and technological outputs to explain the evolution of technology. Int. J. Transitions and Innovation Systems, vol. 4, nos. 1-2, pp. 5-21, http://dx.doi.org/10.1504/IJTIS.2015.074642.

Coccia M. 2016. Problem-driven innovations in drug discovery: co-evolution of the patterns of radical innovation with the evolution of problems, Health Policy and Technology, vol. 5, n. 2, pp. 143-155. https://doi.org/10.1016/j.hlpt.2016.02.003

Coccia M. 2016a. Radical innovations as drivers of breakthroughs: characteristics and properties of the management of technology leading to superior organizational performance in the discovery process of R\&D labs, Technology Analysis \& Strategic Management, vol. 28, n. 4, pp. 381-395, https://doi.org/10.1080/09537325.2015.1095287

Coccia M. 2017. Varieties of capitalism's theory of innovation and a conceptual integration with leadershiporiented executives: the relation between typologies of executive, technological and socioeconomic performances. Int. J. Public Sector Performance Management, Vol. 3, No. 2, pp. $148-168$. https://doi.org/10.1504/IJPSPM.2017.084672 
Coccia M. 2017a. Disruptive firms and industrial change, Journal of Economic and Social Thought, vol. 4, n. 4, pp. 437-450, http://dx.doi.org/10.1453/jest.v4i4.1511

Coccia M. 2017b. New directions in measurement of economic growth, development and under development, Journal of Economics and Political Economy, vol. 4, n. 4, pp. 382-395, http://dx.doi.org/10.1453/jepe.v4i4.1533

Coccia M. 2017c. Sources of disruptive technologies for industrial change. L'industria -rivista di economia e politica industriale, vol. 38, n. 1, pp. 97-120, DOI: 10.1430/87140

Coccia M. 2017d. Sources of technological innovation: Radical and incremental innovation problem-driven to support competitive advantage of firms. Technology Analysis \& Strategic Management, vol. 29, n. 9, pp. 10481061, https://doi.org/10.1080/09537325.2016.1268682

Coccia M. 2018. An introduction to the methods of inquiry in social sciences, Journal of Social and Administrative Sciences, vol. 5, n. 2, pp. 116-126, http://dx.doi.org/10.1453/jsas.v5i2.1651

Coccia M. 2018a. An introduction to the theories of institutional change, Journal of Economics Library, vol. 5, n. 4, pp. 337-344, http://dx.doi.org/10.1453/jel.v5i4.1788

Coccia M. 2018b. Motivations of scientific research in society. Journal of Social and Administrative Sciences, vol. 5, n. 3, pp. 196-216. http://dx.doi.org/10.1453/jsas.v5i3.1680

Coccia M. 2019. Why do nations produce science advances and new technology? Technology in society, vol. 59, November, 101124, pp. 1-9, https://doi.org/10.1016/j.techsoc.2019.03.007

Coccia M. 2019a. The theory of technological parasitism for the measurement of the evolution of technology and technological forecasting, Technological Forecasting and Social Change, vol. 141, pp. 289-304, https://doi.org/10.1016/j.techfore.2018.12.012

Coccia M. 2019b. A Theory of classification and evolution of technologies within a Generalized Darwinism,

Technology Analysis \& Strategic Management, vol. 31, n. 5, pp. 517-531, http://dx.doi.org/10.1080/09537325.2018.1523385

Coccia M. 2019c. Theories of Development. A. Farazmand (ed.), Global Encyclopedia of Public Administration, Public Policy, and Governance, Springer Nature, https://doi.org/10.1007/978-3-319-31816-5_939-1

Coccia M. 2020. An index to quantify environmental risk of exposure to future epidemics of the COVID-19 and similar viral agents: Theory and Practice. Environmental Research, volume 191, December, Article number 110155. https://doi.org/10.1016/j.envres.2020.110155

Coccia M. 2020a. Factors determining the diffusion of COVID-19 and suggested strategy to prevent future accelerated viral infectivity similar to COVID. Science of The Total Environment, vol. 729, n.138474, https://doi.org/10.1016/j.scitotenv.2020.138474.

Coccia M. 2020b. How (Un)sustainable Environments are Related to the Diffusion of COVID-19: The Relation between Coronavirus Disease 2019, Air Pollution, Wind Resource and Energy. Sustainability 2020, 12, 9709; doi:10.3390/su12229709

Coccia M. 2020c. How do environmental, demographic, and geographical factors influence the spread of COVID-19. Journal of Social and Administrative Sciences - J. Adm. Soc. Sci. - JSAS - vol. 7, no. 3, pp. 169209. http://dx.doi.org/10.1453/jsas.v7i3.2018

Coccia M. 2020d. Destructive Technologies for Industrial and Corporate Change. In: Farazmand A. (eds), Global Encyclopedia of Public Administration, Public Policy, and Governance. Springer, Cham, https://doi.org/10.1007/978-3-319-31816-5_3972-1

Coccia M. 2020e. Deep learning technology for improving cancer care in society: New directions in cancer imaging driven by artificial intelligence. Technology in Society, vol. 60, February, pp. 1-11, art. n. 101198, https://doi.org/10.1016/j.techsoc.2019.101198 
Coccia M. 2021. Effects of the spread of COVID-19 on public health of polluted cities: results of the first wave for explaining the dejà vu in the second wave of COVID-19 pandemic and epidemics of future vital agents. Environmental Science and Pollution Research. https://doi.org/10.1007/s11356-020-11662-7

Coccia M. 2021a. Pandemic Prevention: Lessons from COVID-19. Encyclopedia 2021, 1, 433-444. MDPI, Basel, Switzerland, Encyclopedia of COVID-19 ISSN 2673-8392, open access journal, (https://www.mdpi.com/journal/encyclopedia) https://doi.org/10.3390/encyclopedia1020036

Coccia M. 2021b. How do low wind speeds and high levels of air pollution support the spread of COVID-19? Atmospheric Pollution Research, vol. 12, n.1, pp. 437-445., https://doi.org/10.1016/j.apr.2020.10.002.

Coccia M. 2021c. The relation between length of lockdown, numbers of infected people and deaths of COVID19, and economic growth of countries: Lessons learned to cope with future pandemics similar to Covid-19. Science of The Total Environment, Available online 12 February 2021, 145801. https://doi.org/10.1016/j.scitotenv.2021.145801

Coccia M. 2021d. The impact of first and second wave of the COVID-19 pandemic: comparative analysis to support control measures to cope with negative effects of future infectious diseases in society. Environmental Research, vol. 197, June, Article number 111099, PII S0013-9351(21)00393-5, https://doi.org/10.1016/j.envres.2021.111099

Coccia M. 2021e. High health expenditures and low exposure of population to air pollution as critical factors that can reduce fatality rate in COVID-19 pandemic crisis: a global analysis Environmental Research, vol. 199, Article number 111339, https://doi.org/10.1016/j.envres.2021.111339

Coccia M. 2021f. Comparative Critical Decisions in Management. In: Farazmand A. (eds), Global Encyclopedia of Public Administration, Public Policy, and Governance. Springer Nature Switzerland AG 2020, Springer, Cham. ISBN: 978-3-319-20927-2, online ISBN 978-3-319-31816-5. https://doi.org/10.1007/978-3-319-318165_3969-1

Coccia M. 2021g. How a Good Governance of Institutions Can Reduce Poverty and Inequality in Society? In Nezameddin Faghih, Ali Hussein Samadi (Editor) Legal-Economic Institutions, Entrepreneurship, and Management, Perspectives on the Dynamics of Institutional Change from Emerging Markets, Springer Nature Switzerland AG 2021, ISSN 1431-1941 ISSN 2197-716X (electronic) DOI 978-3-030-60978-8_4, ISBN 978-3030-60977-1 ISBN 978-3-030-60978-8 (eBook) https://doi.org/10.1007/978-3-030-60978-8, pp. 65-94

Coccia M. 2021i. The effects of atmospheric stability with low wind speed and of air pollution on the accelerated transmission dynamics of COVID-19. International Journal of Environmental Studies, vol. 78, n. 1, pp. 1-27, https://doi.org/10.1080/00207233.2020.1802937

Coccia M. 2022. Preparedness of countries to face covid-19 pandemic crisis: Strategic positioning and underlying structural factors to support strategies of prevention of pandemic threats, Environmental Research, Volume 203, n. 111678, ISSN 0013-9351, https://doi.org/10.1016/j.envres.2021.111678.

Coccia M., Bellitto M. 2018. Human progress and its socioeconomic effects in society, Journal of Economic and Social Thought, vol. 5, n. 2, pp. 160-178, http://dx.doi.org/10.1453/jest.v5i2.1649

Coccia M., Cadario E. 2014. Organisational (un)learning of public research labs in turbulent context. International Journal of Innovation and Learning, vol. 15, n. 2, pp.115-129, https://doi.org/10.1504/IJL.2014.059756

Coccia M., Watts J. 2020. A theory of the evolution of technology: technological parasitism and the implications for innovation management, Journal of Engineering and Technology Management, vol. 55, https://doi.org/10.1016/j.jengtecman.2019.11.003

Cylus J., Pantel, D., van Ginneken E. 2021. Who should be vaccinated first? Comparing vaccine prioritization strategies in Israel and European countries using the Covid-19 Health System Response Monitor. Israel journal of health policy research, 10(1), 16. https://doi.org/10.1186 
Dashtbali M., Mirzaie M.2021. A compartmental model that predicts the effect of social distancing and vaccination on controlling COVID-19, Scientific Reports, 11(1),8191

de Vlas, S. J., Coffeng, L. E. 2021. Achieving herd immunity against COVID-19 at the country level by the exit strategy of a phased lift of control. Scientific reports, 11(1), 4445. https://doi.org/10.1038/s41598-021-83492-7

DeRoo, S., Pudalov, N. J., Fu, L. Y. 2020. Planning for a COVID-19 Vaccination Program. JAMA, 323(24), 2458-2459. https://doi.org/10.1001/jama.2020.8711

ECDC 2021. SARS-CoV-2 variants of concern as of 3 June 2021. European Centre for Disease Prevention and Control, https://www.ecdc.europa.eu/en/covid-19/variants-concern (accessed on 10 June 2021).

Engelbrecht, F. A., \& Scholes, R. J. 2021. Test for Covid-19 seasonality and the risk of second waves. One health (Amsterdam, Netherlands), 12, 100202. https://doi.org/10.1016/j.onehlt.2020.100202

Ethgen O., Rémy V., Wargo K. 2018. Vaccination budget in Europe: an update. Human vaccines \& immunotherapeutics, 14(12), 2911-2915. https://doi.org/10.1080/21645515.2018.1504528

Fontanet A., Cauchemez, S. 2020. COVID-19 herd immunity: where are we?. Nature reviews. Immunology, 20(10), 583-584. https://doi.org/10.1038/s41577-020-00451-5

Frederiksen L., Zhang Y., Foged C., Thakur A. 2020. The Long Road Toward COVID-19 Herd Immunity: Vaccine Platform Technologies and Mass Immunization Strategies. Frontiers in immunology, 11, 1817. https://doi.org/10.3389/fimmu.2020.01817

Freed G. L. 2021. Actionable lessons for the US COVID vaccine program. Israel journal of health policy research, 10(1), 14. https://doi.org/10.1186/s13584-021-00452-2

GAVI 2021. THE FOUR MAIN TYPES OF COVID-19 VACCINE. https://www.gavi.org/vaccineswork/thereare-four-types-covid-19-vaccines-heres-how-they-work (accessed 6 September 2021).

Harrison E. A., Wu J. W. 2020. Vaccine confidence in the time of COVID-19. European journal of epidemiology, 35(4), 325-330. https://doi.org/10.1007/s10654-020-00634-3

Heaton P. M. 2020. The Covid-19 Vaccine-Development Multiverse. The New England journal of medicine, 383(20), 1986-1988. https://doi.org/10.1056/NEJMe2025111

Jeyanathan M, Afkhami S, Smaill F, Miller MS, Lichty BD, Xing Z. 2020. Immunological considerations for COVID-19 vaccine strategies. Nat Rev Immunol. 20(10):615-632. doi: 10.1038/s41577-020-00434-6.

Johns Hopkins Center for System Science and Engineering, 2021. Coronavirus COVID-19 Global Cases, https://gisanddata.maps.arcgis.com/apps/opsdashboard/index.html\#/bda7594740fd40299423467b48e9ecf6 (accessed in 4 January 2021).

Jones D., Helmreich S. 2020. A history of herd immunity. Lancet (London, England), 396(10254), 810-811. https://doi.org/10.1016/S0140-6736(20)31924-3

Kluge H. H. P., Nitzan D., Azzopardi-Muscat N. 2020. COVID-19: reflecting on experience and anticipating the next steps. A perspective from the WHO Regional Office for Europe. Eurohealth 2020; 26(2).

Komaroff A. 2020. Why are mRNA vaccines so exciting? Harvard Health Blog, https:/www.health.harvard.edu/blog/why-are-mrna-vaccines-so-exciting-2020121021599 (Posted December 10, 2020, 2:30 pm, Updated December 18, 2020, 7:52 pm).

Kwok K. O., Lai F., Wei W. I., Wong S., Tang J. 2020. Herd immunity - estimating the level required to halt the COVID-19 epidemics in affected countries. The Journal of infection, 80(6), e32-e33. https://doi.org/10.1016/j.jinf.2020.03.027

Liu, X., Huang, J., Li, C., Zhao, Y., Wang, D., Huang, Z., \& Yang, K. 2021. The role of seasonality in the spread of COVID-19 pandemic. Environmental research, 195, 110874. https://doi.org/10.1016/j.envres.2021.110874 
Mallapaty S. 2021. Are COVID vaccination programmes working? Scientists seek first clues. Nature, 589(7843), 504-505. https://doi.org/10.1038/d41586-021-00140-w

MAYO CLINIC 2021. Different types of COVID-19 vaccines: How they work. https://www.mayoclinic.org/diseases-conditions/coronavirus/in-depth/different-types-of-covid-19-vaccines/art20506465 (accessed 6 September 2021).

McKee, M., Rajan, S.2021. What can we learn from Israel's rapid roll out of COVID 19 vaccination? Israel Journal of Health Policy Research, 10(1),5

Oliver S., Gargano J., Marin M. et al. 2020. The Advisory Committee on Immunization Practices' Interim Recommendation for Use of Pfizer-BioNTech COVID-19 Vaccine — United States, December 2020. MMWR Morb Mortal Wkly Rep 2020;69:1922-1924. DOI: http://dx.doi.org/10.15585/mmwr.mm6950e2external icon.

Our World in Data 2021. Coronavirus (COVID-19) Vaccinations - Statistics and Research - Our World in Data https://ourworldindata.org/covid-vaccinations (Accessed March 2020)

Prieto Curiel, R., González Ramírez, H. 2021. Vaccination strategies against COVID-19 and the diffusion of anti-vaccination views, Scientific Reports 11(1),6626

Randolph H. E., Barreiro L. B. 2020. Herd immunity: understanding COVID-19. Immunity 52, 737-741

Redwan E. M. 2021. COVID-19 pandemic and vaccination build herd immunity. European review for medical and pharmacological sciences, 25(2), 577-579. https://doi.org/10.26355/eurrev_202101_24613

Ritchie H., Ortiz-Ospina E., Beltekian D., Mathieu E., Hasel J., Macdonald B., Giattino C., Roser, M. 2020. Policy Responses to the Coronavirus Pandemic. Our World in Data, Statistics and Research. Retrieved July 7 , 2020, from https://ourworldindata.org/policy-responses-covid

Rosen B., Waitzberg R., Israeli A.2021. Israel's rapid rollout of vaccinations for COVID-19, Israel Journal of Health Policy Research10(1),6

Rossman, H., Shilo, S., Meir, T. et al. 2021. COVID-19 dynamics after a national immunization program in Israel. Nat Med (2021). https://doi.org/10.1038/s41591-021-01337-2

Sagan A., Thomas S., McKee M., Karanikolos M., Azzopardi-Muscat N., de la Mata I., Figueras J. 2020. COVID-19 and health systems resilience: lessons going forwards, Eurohealth 2020; 26(2).

Seligman B, Ferranna M, Bloom DE 2021. Social determinants of mortality from COVID-19: A simulation study using NHANES. PLoS Med 18(1): e1003490. doi:10.1371/journal.pmed.1003490

Sim, F. 2021. Early Covid-19 vaccination rollout: a commentary from England, Israel Journal of Health Policy Research, 10(1), 18

U.S. Department of Health \& Human Services, 2021. Public health Emergency-Executive Summary, https://www.phe.gov/Preparedness/planning/nivms/Pages/executive-summary.aspx (accessed March 2021).

Vignesh, R., Shankar, E. M., Velu, V., Thyagarajan, S. P. 2020. Is Herd Immunity Against SARS-CoV-2 a Silver Lining?. Frontiers in immunology, 11, 586781. https://doi.org/10.3389/fimmu.2020.586781

Vinceti, M., Filippini, T., Rothman, K. J., Di Federico, S., \& Orsini, N. 2021. SARS-CoV-2 infection incidence during the first and second COVID-19 waves in Italy. Environmental research, 197, 111097. https://doi.org/10.1016/j.envres.2021.111097

Whittaker, C., Kamaura, L. T., Takecian, P. L., da Silva Peixoto, P., Oikawa, M. K., Nishiya, A. S., ... Sabino, E. C. 2021. Three-quarters attack rate of SARS-CoV-2 in the Brazilian Amazon during a largely unmitigated epidemic. Science (New York, N.Y.), 371(6526), 288-292. https://doi.org/10.1126/science.abe9728

Williams G. A., Ulla Díez S. M., Figueras J., Lessof S. 2020. Translating evidence into policy during the covid19 pandemic: bridging science and policy (and politics). Eurohealth 2020; 26(2). 